\title{
Do boi à soja: agrotóxicos e riscos à saúde na Amazônia
} mato-grossense

\section{From cattle to soybean: pesticides and health risks in the Amazonian Region of Mato Grosso State, Brazil}

Marla Leci Weihs - Doutora em Desenvolvimento Sustentável, pela Universidade de Brasília (UnB). Professora da Faculdade de Ciências Biológicas e Agrárias da Universidade do Estado de Mato Grosso (UNEMAT). E-mail: marla@unemat.br

\section{Resumo}

Em função da pavimentação da BR-163 (Cuiabá-Santarém) e da abertura do Porto de Miritituba, no estado do Pará, fazendas de gado do extremo norte de Mato Grosso vêm sendo transformadas em lavouras de grãos (sistemas tradicionais consorciados milhosoja). Essa transição gera questionamentos sobre os riscos de reproduzir, na Amazônia, um modelo de produção baseado no uso intensivo de agrotóxicos. Como a expansão das lavouras de soja pode afetar a saúde da presente e futura geração? Como agricultores familiares e fazendeiros percebem os riscos? A pesquisa envolveu $23 \%$ do universo de produtores rurais dos municípios de Alta Floresta, Carlinda e Paranaíta. No plano socioambiental, o modelo de desenvolvimento agrícola nessa fronteira agrícola tem gerado situações altamente paradoxais. Enquanto favorece uma elite agrícola urbana e desconectada da terra, que não se preocupa com os riscos à saúde, associados ao extensivo uso de agrotóxicos, cria perigos ao modo de vida rural, os quais geram preocupações aos agricultores familiares.

\section{Palavra-chave}

Amazônia. Fronteira Agrícola. Soja. Percepção de Risco. Agricultura Familiar.

\begin{abstract}
The paving of BR-163 (Cuiabá-Santarém) and opening of Miritituba Port in Pará State are the causes of cattle farms in the extreme north of Mato Grosso State have being transformed into grain crops (the traditional maize-soybean intercropping systems). This transition raises questions about the risks of reproducing in the Amazon, a production model based on the intensive use of pesticides. How can soybean production affect the health of present and future generations? How do family farmers and big farmers perceive the risks? This research involved $23 \%$ of rural producers in Alta Floresta, Carlinda and Paranaita counties. The agricultural development model at this agricultural frontier has generated highly paradoxical situations at the socio-environmental level. While favoring an urban agricultural elite disconnected from the land, which does not observe health risks associated with the extensive use of agrochemicals, it creates dangers to the rural way of life, which raise concerns for family farmers.
\end{abstract}

\section{Keywords}

Amazon. Agriculture Frontier. Soybean. Risk Perception. Family Farming. 


\section{INTRODUÇÃO}

Por definição legal, o bioma amazônico cobre 60\% dos municípios do estado de Mato Grosso (BRASIL, 2008). A expansão da fronteira agrícola em direção a esse território remete ao início dos anos 1970, quando foram abertas principalmente as rodovias BR-163 e BR-158, conectando o norte e o nordeste do estado às regiões Sul e Sudeste do país. Tratava-se de uma iniciativa do governo militar, cuja finalidade era, entre outros fatores, aliviar a tensão social em outras regiões, gerada pela modernização agrícola, e integrar a Amazônia à economia capitalista globalizada (BECKER, 1988; OLIVEIRA, 2005).

O Brasil assistia à transformação do modelo de produção agrícola causado pela adoção do pacote conhecido como Revolução Verde. No bojo desse processo, constava a incorporação de mecanização, agrotóxicos, fertilizantes, irrigação, sementes híbridas melhoradas, apoio estatal e crédito (PATEL, 2013). Entre as consequências no campo, observava-se o crescimento da concentração da terra, êxodo rural, desemprego e empobrecimento (GRAZIANO DA SILVA, 1982).

$\mathrm{Na}$ região de Alta Floresta (Alta Floresta, Paranaíta e Carlinda), localizada no extremo norte do estado, a gestão da colonização foi entregue a uma empresa, que assumiu a missão de demarcar e promover a ocupação das terras e executar obras de infraestrutura, entre outros (JEPSON, 2006; MIRANDA, 1990). Os camponeses eram atraídos para a região por meio de propagandas, disseminadas principalmente no norte e noroeste do Paraná. A empresa buscava prioritariamente aqueles que possuíam recursos financeiros para a aquisição ou o pagamento da primeira parcela das propriedades (GUIMARÃES NETO, 2002; WEIHS, 2015). Os agricultores que migraram espontaneamente, sem dispor desses recursos, foram assentados posteriormente pelo Instituto Nacional de Colonização e Reforma Agrária (INCRA), no território do atual município de Carlinda (NÉDÉLEC et al., 2019).

Ao longo das décadas de avanço da fronteira agrícola na região, a economia passou por uma série de fases, iniciando em meados da década de 1970, com a conversão da floresta em plantações de café e lavouras "brancas" (feijão, arroz etc.), cujo modelo de produção orientava-se para a subsistência e comercialização do excedente (MIRANDA, 1990). As más condições das estradas e a falta de orientação técnica e, sobretudo, de subsídios para a produção e comercialização, provocaram a falência em uma parcela importante de agricultores, durante as décadas de 1980 e 1990. De forma geral, as famílias que subsistiram na atividade foram aquelas que mudaram a matriz produtiva, 
incorporando, por meio do acesso ao crédito agrícola, a plantação de pastagem e a aquisição de gado leiteiro (SABOURIN, 2006).

$\mathrm{Na}$ fase atual, distinguem-se principalmente duas categorias de produtores. De uma parte, agricultores familiares, que, em grande medida, se encontram estáveis na atividade agropecuária, embora enfrentem diferentes desafios, associados, sobretudo às limitações de acesso ao crédito, à escassez de mão de obra em função do envelhecimento dos membros da família e à necessidade de reorientação da atividade, face à problemática ambiental (BRASIL, 2005; BERNASCONI; SANTOS; RODRIGUES, 2009). De outra parte, a categoria dos médios e grandes proprietários, entre os quais constam produtores de gado de corte e de grãos - parte deles, de outras regiões -, que protagonizam a expansão das lavouras comerciais, por meio da aquisição ou arrendamento de terras, com ou sem conflitos, pertencentes ou ocupadas por grupos socioeconomicamente mais vulneráveis (e.g., agricultores familiares, assentados de projetos de reforma agrária etc.) (COY; KLINGLER, 2014).

Embora tenha variado em função do tipo e volume aplicado, o uso de agrotóxicos permeia todas essas fases de ocupação da fronteira agrícola. No início, a produção de café, bem como o risco de doenças transmitidas por mosquitos (malária e leishmaniose tegumentar etc.), determinou o uso de inseticidas organoclorados, como DDT (diclorodifeniltricloroetano) e seus similares, a exemplo do BHC (hexaclorobenzeno), aldrin e dieldrin, entre outros (WEIHS; SAYAGO, 2015). Não há estimativas da quantidade de inseticidas lançada nos ecossistemas nos mais de 20 anos de sua utilização na região. Na agricultura, o emprego de DDT foi proibido em 1985 (BRASIL, 1985) e em programas de controle de doenças transmitidas por insetos, em 1998 (BRASIL, 1998). A alta resistência desses produtos à degradação química e biológica prolongou a sua persistência nos ecossistemas. No caso do DDT, estudos estimaram uma semivida de cerca de 20 anos (HARNER et al., 1999; MARTIJN; BAKKER; SCHREUDER, 1993). Pesquisas recentes indicam que peixes do rio Teles Pires e de alguns de seus afluentes, localizados na região deste estudo, ainda apresentam doses do produto em concentrações superiores aos limites aceitos pela Organização Mundial da Saúde (OMS) (DALLA VILLA et al., 2006; D’AMATO; TORRES; MALM, 2007).

Até meados do ano 2000, a limpeza anual das pastagens, usada para eliminar ervas rejeitadas pelo gado, era realizada com o uso do fogo. A deflagração de mais de 10 grandes operações policiais e a intensificação da fiscalização ambiental, depois de 2005, redefiniu a forma como os agricultores desenvolveriam essa atividade, ampliando o uso de herbicidas (SILVA et al., 2011). 
A longa exposição dos trabalhadores a pesticidas acumulados nos ecossistemas pode ter contribuído, direta ou indiretamente, com as atuais taxas de incidência de doenças crônicas respiratórias, circulatórias, endócrinas e de neoplasias (tumores benignos e malignos) na região de Alta Floresta (IGNOT'TI et al., 2010; MATO GROSSO, 2011, 2013, 2015). Pesquisas sugerem que, nessa região, a transição epidemiológica - embora incompleta, porque o que se revela na fronteira agrícola amazônica é um mosaico, em que se mantêm algumas doenças da pobreza ${ }^{1}$, enquanto aumenta a incidência de Doenças Crônicas Não Transmissíveis (DCNT) ${ }^{2}$-, vem sofrendo importantes influências das mudanças ambientais (WANIEZ, 2007; WEIHS; SAYAGO, 2015; WEIHS; SAYAGO; TOURRAND, 2017). Nessa abordagem, o atual quadro de DCNT pode ter sido condicionado pela intensa e longínqua exposição da população a contaminantes tóxicos, como os resíduos agroquímicos (WEIHS, 2015; WEIHS; SAYAGO; TOURRAND, 2017).

Como os métodos produtivos usados na pecuária, atualmente em curso, e os que estão sendo colocados em prática nas lavouras de grãos, em expansão, podem afetar a saúde da presente e da futura geração? Qual é a percepção dos riscos e quem são os produtores mais preocupados com as externalidades negativas produzidas pela expansão das lavouras de soja na região? São as questões que este artigo busca responder. Trata-se da análise de uma parcela dos resultados do projeto "Promoting a risk-free socio-environmental supply to shed - a sustainable territorial approach in Northern Mato Grosso", desenvolvido por meio de uma parceria entre o Instituto Centro de Vida (ICV) e a Universidade do Estado de Mato Grosso (UNEMAT). A investigação baseou-se na aplicação de questionários a 67 agricultores familiares e 31 proprietários de médias e grandes propriedades, denominados fazendeiros.

A nossa hipótese é que os agricultores familiares formam o grupo mais preocupado com as externalidades negativas produzidas pela expansão das lavouras de grãos na região. O grupo dos fazendeiros, por sua vez, possivelmente secundarize o perigo do consumo de agrotóxicos à saúde humana e dos ecossistemas, por estar mais integrado aos sistemas modernos de produção e gerir suas atividades de forma empresarial.

\footnotetext{
Trata-se de um conjunto de doenças que incidem desproporcionalmente sobre os grupos mais pobres da sociedade. Exemplos: tuberculose, hanseníase, esquistossomose, malária e as verminoses, entre outras.

2 Conjunto de doenças que configuram a principal causa de morte no mundo, na atualidade. São exemplos, as doenças (como ataques cardíacos e acidentes vasculares cerebrais), câncer, doenças respiratórias crônicas (como doença pulmonar obstrutiva crônica e asma) e diabetes. Entre os seus determinantes estão, principalmente, comportamento, meio ambiente e perfil genético.
} 
A nossa segunda hipótese é que a expansão das lavouras de grãos é um fator preocupante face aos novos riscos à saúde das populações, associados, sobretudo, ao aumento do volume de agrotóxicos consumido.

\section{SOBRE INDUSTRIALIZAÇÃO, MEIO AMBIENTE E RISCOS}

É cada vez mais ampla e diversificada a literatura social contemporânea que aborda o fenômeno do industrialismo como um precursor de mudanças estruturais que afetam os campos da cultura (LIPOVETSKY; SERROY, 2011), sociedade e meio ambiente (GIDDENS, 1991; BECK, 2010), entre outros. Nessa abordagem, o industrialismo é compreendido, em primeira mão, como o resultado do desenvolvimento de uma sociedade capitalista e, em segunda, como a causa estrutural das formas modernas de degradação ambiental, produzidas pelas transformações da indústria e agricultura, entre outras (GIDDENS, 1991; GOLDBLATT, 1996).

Na perspectiva ambiental, retoma-se a antiga discussão da relação homemnatureza, mas, desta vez, voltada principalmente aos efeitos e riscos das ações antrópicas. Fenômenos como a globalização da economia e a emergência da preocupação com as mudanças climáticas reconfiguram esse olhar das ciências para os problemas ambientais (FORTES; RIBEIRO, 2014). Na abordagem contemporânea, a natureza não é mais tratada como um bem natural, situado fora do escopo da ação humana, mas, ao contrário, a natureza é percebida como um bem que foi, ao longo dos últimos séculos, absorvido e transformado pelo sistema tecnológico-industrial (BECK, 2010). O que se perpetua, a partir desta concepção, é que, na perspectiva da ciência, a natureza não mais existe, porque não existem mais espaços virgens. Independentemente da intensidade, todos os ecossistemas do planeta já foram alterados pela ação humana (WEIHS, 2015).

No caldeirão dos novos conceitos emerge a compreensão do risco como objeto social. Trata-se de uma visão atribuída à modernidade tardia (ou pósmoderna), fundada, sobretudo, pelos sociólogos Anthony Giddens e Ulrich Beck. O risco é, nessa perspectiva, definido como a percepção do perigo. São as representações mentais, apreendidas por indivíduos, comunidades ou uma sociedade que convive com perigos emergentes (VEYRET, 2007). A incorporação dos olhares e saberes, não diretamente ligados ao mundo científico, resulta da percepção de que a ambiguidade e a invisibilidade de muitos riscos contemporâneos tornam difícil obter a certeza que se gostaria de ter, somente com base em provas científicas (HANNIGAN, 1995; BECK, 2010). 
Os riscos não estão associados à prevalência de perigos para a vida, ao nível da existência dos indivíduos, mas se relacionam à expectativa de vida e ao grau de liberdade em relação à exposição aos subprodutos da "industrialização da natureza", como os contaminantes químicos, físicos ou biológicos, consumidos de forma institucionalizada pela agricultura e indústria. Em síntese, “o risco representa a percepção de uma potencialidade de crise, de acidente ou catástrofe, o que não é, portanto, o acontecimento catastrófico propriamente dito" (VEYRET, 2007, p. 11).

As percepções de risco diferem de acordo com as diferentes oportunidades de vida dos indivíduos, ou seja, o risco é percebido a partir das diferenças de poder entre os atores sociais. "Os trabalhadores e os patrões veem os riscos da saúde ambiental no local de trabalho sob perspectivas diferentes" (HANNIGAN, 1995, p. 127). Mas, como trabalhadores e patrões constroem a sua própria percepção de risco? No campo cognitivo, segundo Merleau-Ponty (1994), a construção da percepção se faz a partir da apreensão do sentido ou dos sentidos, que é feita pelo corpo, e elaborada na sua relação com o mundo da cultura e das relações sociais. A percepção é construída, portanto, a partir da experiência do sujeito que olha, sente e reconhece o espaço como expressivo e simbólico (NÓBREGA, 2008). Para construí-la, esse sujeito explora o campo da cultura, saberes, artes e ciências, entre outros. As suas principais influências vêm da sua relação com amigos, família e vizinhança, além da interação com figuras públicas (professores, pesquisadores, gestores públicos etc.) e meios de comunicação (os canais de mídia em geral), que funcionam como filtros na difusão da informação na comunidade (HANNIGAN, 1995; SJÖBERG, 1998).

\section{2 ÁREA DE ESTUDO}

Os três municípios que compõem a região de Alta Floresta somam uma área de 1.616 mil hectares (Figura 1). É um território considerado rico em recursos hídricos quando comparado aos demais municípios do estado de Mato Grosso produtores de commodities agrícolas (soja, milho e algodão, entre outras). Em Alta Floresta, o município de maior dimensão territorial (896 mil hectares), existem 6.454 nascentes que alimentam, em conjunto com outras, cerca de 11 mil quilômetros de rios. Em termos biofísicos, esses ambientes apresentam importante nível de degradação. Dos cerca de 116 mil hectares de Áreas de Proteção Permanente (APP), 58 mil hectares (42\%) se encontram em algum estágio de degradação (vegetação degradada e/ou solo exposto) ou completamente ocupados por pastagens ou lavouras (Figura 3) (BERNASCONI; ADAB; MICOL, 2008). 
Figura 1 - Localização da região de Alta Floresta, no norte do estado de Mato Grosso: municípios de Alta Floresta, Carlinda e Paranaíta

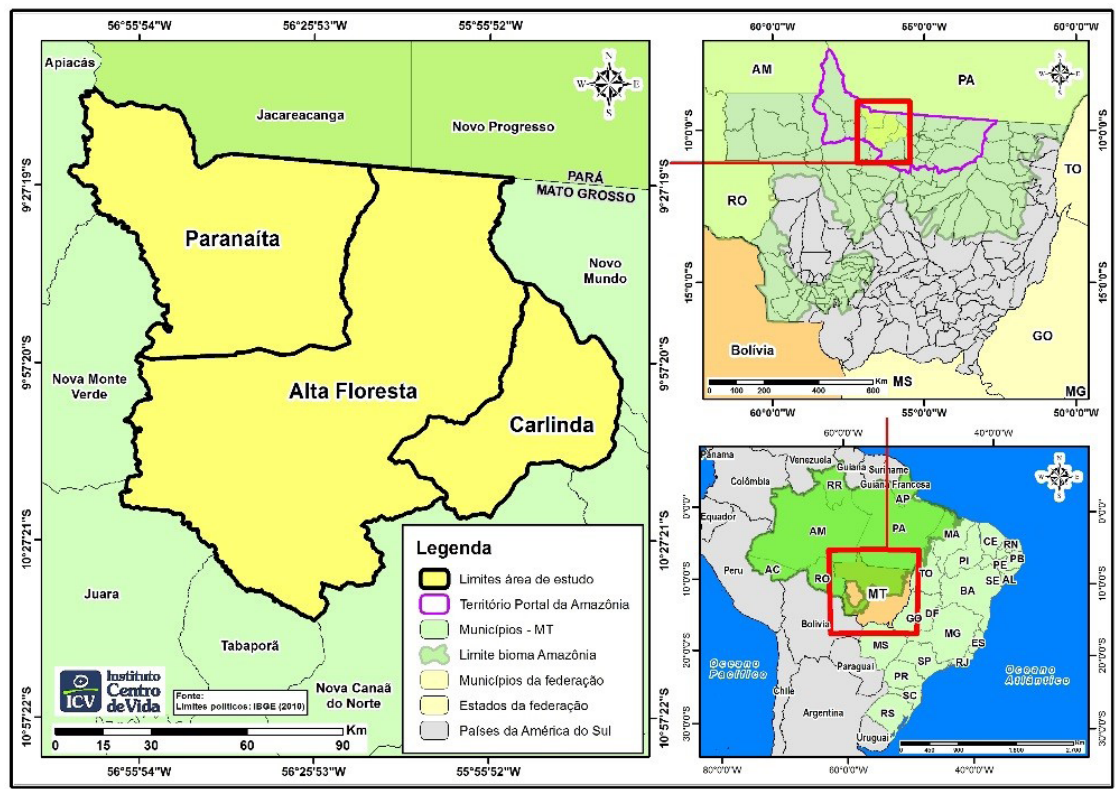

Fonte: Tambosi et al. (2016).

Figura 2 - Recursos hídricos da região de Alta Floresta, no norte do estado de Mato Grosso

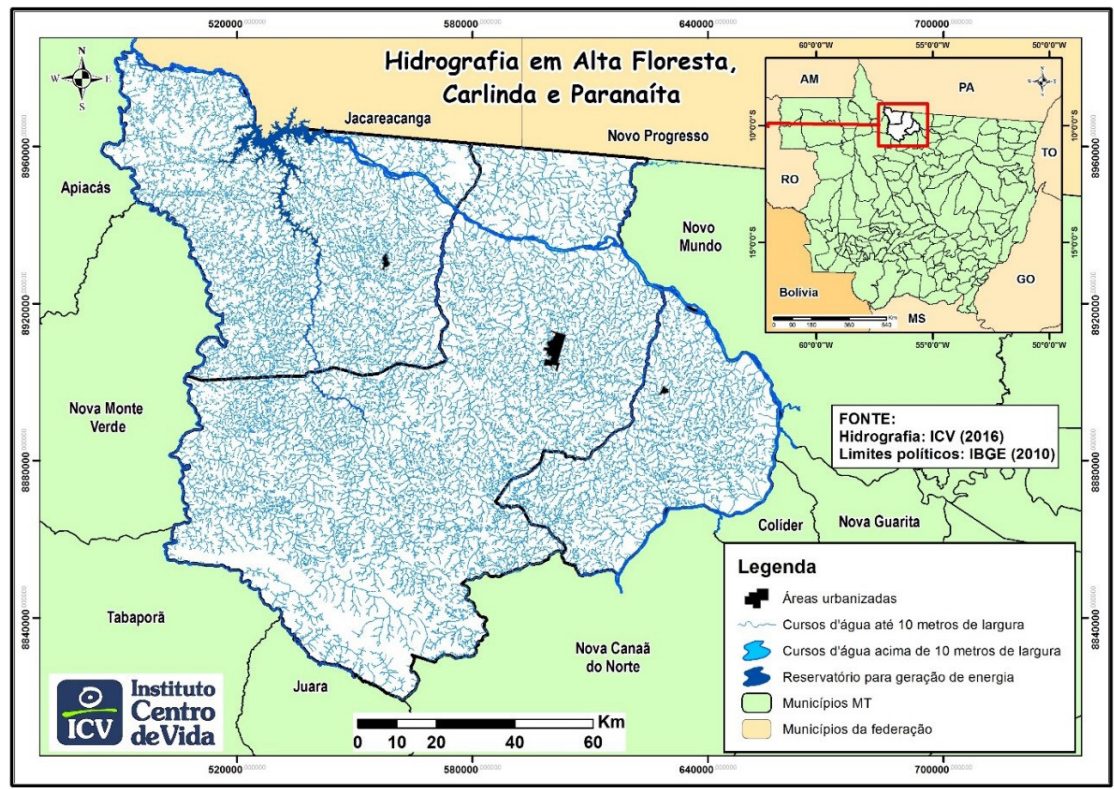

Fonte: Tambosi et al. (2016). 
Figura 3 - Remanescentes de vegetação nativa e ocupação agrícola (área de uso consolidado) da região de Alta Floresta, no norte do estado de Mato Grosso

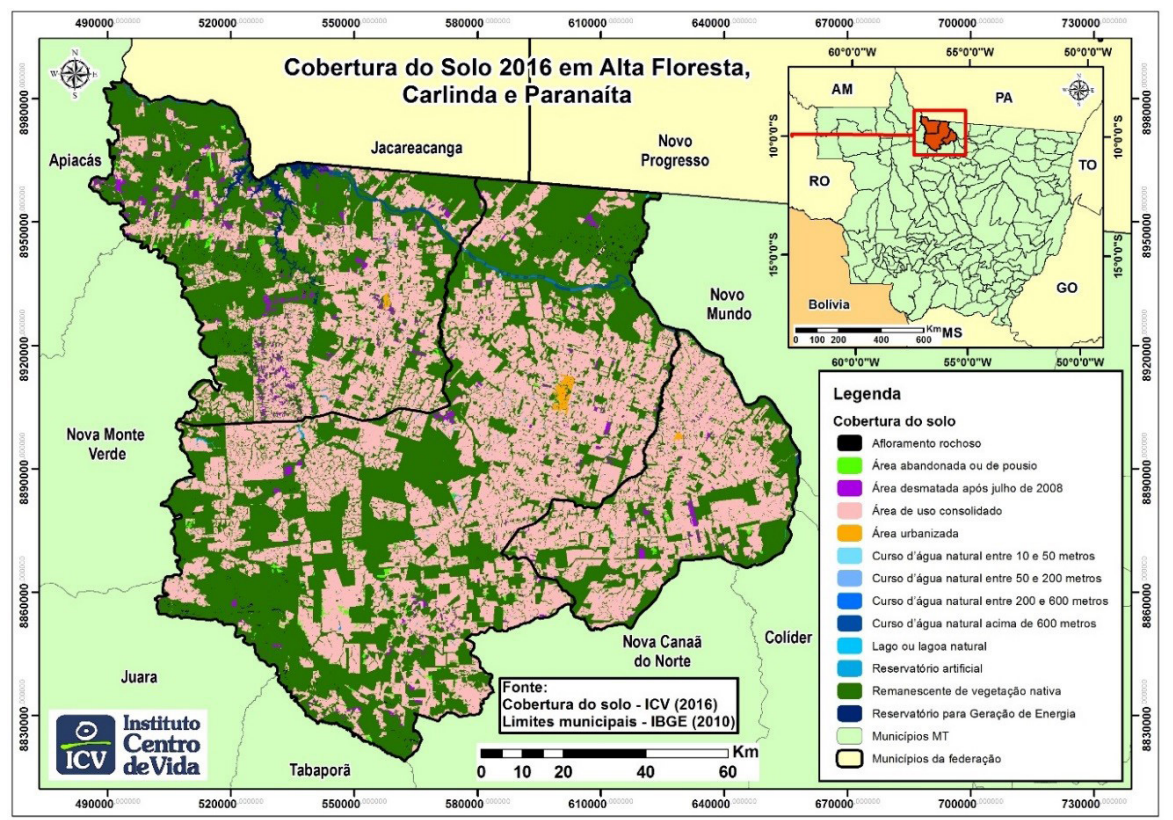

Fonte: Tambosi et al. (2016).

A economia da região está baseada principalmente na produção de gado de corte, nas grandes e médias propriedades, e de gado leiteiro, na agricultura familiar. Segundo dados do Instituto Brasileiro de Geografia e Estatística (IBGE, 2019), os três municípios somavam, em 2016, um efetivo bovino estimado em 1.408 .749 cabeças, sendo a maior parte $(50,15 \%)$ produzida no município de Alta Floresta. O volume de carne exportado pelo conjunto de municípios era de cerca de seis mil toneladas, tendo como principais destinos países como Hong Kong, Egito e Estados Unidos (MDIC, 2016). A produção anual de leite aproximava-se de 32 milhões de litros (IBGE, 2019). A área de produção de soja aumentou 409\% em quatro anos (2013-2016). Entre outros fatores, a expansão dessas lavouras de grãos diminuiu o cartel bovino em cerca de $8 \%$, no mesmo período (IBGE, 2019).

$\mathrm{Na}$ região, há forte predomínio da pequena propriedade em termos de número de estabelecimentos: mais de $90 \%$ das propriedades possuem área inferior a 400 ha. Em Carlinda, esse quantitativo chega a 96\%. No entanto, observa-se que, apesar da importância da pequena propriedade, em termos de número de estabelecimentos, o setor ocupa uma área total extremamente reduzida quando 
comparada com a área ocupada pelas médias e grandes propriedades. Ao todo, 67\% do território são ocupados por áreas com dimensão superior a 400 ha. Em Alta Floresta, onde 91\% dos estabelecimentos são pequenos, os médios e grandes estabelecimentos ocupam $76 \%$ da área do território de ocupação agrícola.

\section{DESENHO DA PESQUISA E ITINERÁRIO DE CAMPO}

Os roteiros de entrevistas foram elaborados com base nos critérios de certificação adotados pela Round Table on Responsible Soy (RTRS) ${ }^{3}$. Os dados referentes aos riscos à saúde foram obtidos por meio de um conjunto de perguntas sobre os principais insumos (herbicidas, inseticidas, fungicidas, fertilizantes, calcário, sementes geneticamente modificadas, vacinas, medicamentos e inseminação artificial) usados na propriedade. Para a análise, os dados sobre o uso de agroquímicos foram cruzados com as informações referentes às propriedades.

Os participantes da pesquisa foram escolhidos por conveniência (amostra não probabilística, do tipo intencional). Os questionários foram aplicados entre os meses de junho e agosto de 2016. Em algumas entrevistas as respostas foram anotadas manualmente em papel e, quando autorizadas, as conversas foram gravadas. Trechos das gravações foram transcritos e categorizados, para análise de conteúdo. Para identificar seus autores, foram usadas siglas que definem se é um agricultor familiar (AF) ou um fazendeiro (F), seguidas do número do questionário.

A investigação envolveu $23 \%$ do universo de produtores rurais da região de Alta Floresta, sendo 67 agricultores de até quatro módulos fiscais (400 hectares), que se autodenominaram agricultores familiares, e 31 proprietários de áreas superiores a quatro módulos fiscais, denominados fazendeiros. A distinção entre os dois grupos também levou em consideração a distribuição do trabalho. Aqueles que possuíam propriedades com área inferior a 400 ha, mas a mão de obra era atribuída majoritariamente a empregados temporários e/ou contratados e cuja produção principal era de commodities (carne, soja e/ou milho), foram classificados como fazendeiros. Essa distinção baseou-se nas diretrizes das políticas públicas usadas para caracterizar o grupo dos agricultores familiares e definidas na Lei no 11.326 , de julho de 2006.

Uma organização da sociedade civil que promove certificação da produção de soja com o objetivo de assegurar melhores práticas ambientais, sociais e econômicas, fundamentadas em princípios e critérios internacionais. 


\section{OS AGRICULTORES FAMILIARES ENVOLVIDOS NA PESQUISA: QUEM SÃO?}

O grupo de agricultores familiares foi constituído em 49,25\% por homens e em $50,75 \%$ por mulheres. A maior parte deles, $57 \%$, possuía idade acima de 40 anos. Parcela significativa dessa população (10,45\%) não sabe ler e o nível de escolaridade da maioria $(62,7 \%)$ se limita ao ensino fundamental. O menor nível de escolaridade é encontrado em Carlinda.

A área média das propriedades é de 52 ha, sendo que a menor delas tem 02 ha e a maior, 242 ha. As famílias são proprietárias da terra em 97\% dos casos. O leite é a principal atividade econômica em 56,75\% dos estabelecimentos agrícolas. Aproximadamente $70 \%$ dos produtores participam de organizações sociais. É significativa a parcela de famílias que se mantém economicamente por meio de aposentadorias $(27,02 \%)$.

A produção de hortaliças predomina em cinco das 67 propriedades. Em outras, há cultivo de mandioca (para a produção de farinha), abóbora, batata-doce, feijão-de-corda, café e frutas, como maracujá, mamão, banana, laranja, mexerica e cupuaçu. De forma geral, a fruticultura não é vista como uma fonte de renda. Para os agricultores, ela serve para alimentar a família e para ser distribuída aos vizinhos e visitantes. As exceções existem em Carlinda, onde uma pequena parcela da produção de frutas é adquirida pela Cooperativa Agropecuária Mista Terranova Ltda. (COOPERNOVA) para a produção de polpas. Também nesse município há produtores que vendem as verduras, legumes e frutas diretamente para os consumidores por meio de feiras locais e de um Sistema de Comercialização Solidária (SISCOS). Não há cultivo de soja ou arrendamento da terra para tal atividade.

\section{OS FAZENDEIROS: QUEM SÃO?}

O grupo dos fazendeiros foi prioritariamente formado por homens (93,55\%), com idade superior a 40 anos, sendo que 38,7\% deles possuía idade acima de 60 anos. A maioria $(96,77 \%$ ) dessa população sabe ler, sendo que $45,16 \%$ possui ensino fundamental, $32,25 \%$ ensino médio e 12,9\% ensino superior. Apenas 32,25\% dessas famílias residem na propriedade.

As propriedades têm, em média, 988 ha, sendo que a menor delas tem 78,51 ha e a maior, 10.000 ha. Todos os proprietários possuem o título da terra ou documento equivalente. A pecuária é a principal fonte de renda em 37,5\% das propriedades. A soja é produzida em $25 \%$ das propriedades. Mais de $30 \%$ dos produtores já arrendam uma parcela das terras para terceiros. 


\section{O USO DOS AGROTÓXICOS}

Com base na dimensão das áreas produtivas (conforme as respostas positivas para o uso de pesticidas, obtidas nas entrevistas), podemos categorizar o uso de agrotóxicos na região. Nas fazendas, os herbicidas são usados em $83,4 \%$ das áreas, enquanto na agricultura familiar esse percentual é de $61,51 \%$. A aplicação de inseticidas e fungicidas, por sua vez, é expressivamente maior nas propriedades que adotam sistemas de produção familiares $(35,22 \%$ e $3,27 \%$, respectivamente), em comparação com a utilização nas fazendas (14,12\% para inseticidas e 2,48\% para fungicidas).

Os líderes de aplicação são as formulações dos herbicidas 2,4-D + picloram e glifosato. Somados, eles cobrem $78 \%$ das áreas que recebem agrotóxicos. $\mathrm{Na}$ agricultura familiar, essas formulações substituem a mão de obra na capina, permitindo que o manejo da produção se mantenha restrito ao núcleo familiar. Além disso, o uso do produto é popular entre os pequenos produtores devido ao baixo custo e eficácia, mesmo em baixas doses (QURRATU; REEHAN, 2016). Nas fazendas, essas formulações são usadas principalmente para controlar as ervas indesejáveis em pastagens ou, no caso do glifosato, o uso está associado à produção de soja geneticamente modificada.

Os inseticidas são usados nas fazendas para controlar insetos que prejudicam a produção de grãos, como soja e milho. Nas pequenas propriedades são usados principalmente na produção de hortaliças e frutas. Entre as formulações utilizadas em áreas mais extensas estão o fipronil e o metomil. Chama a atenção o uso de cipermetrina na agricultura familiar, estendendo-se por uma área ligeiramente superior à área das médias e grandes propriedades que recebem pulverizações com o mesmo produto.

\section{OS AGROTÓXICOS MAIS USADOS E OS PREJUÍZOOS À SAÚDE}

Atualmente, resíduos do 2,4-D e seus derivados são encontrados em todo o mundo, devido ao seu uso generalizado como herbicida. Os danos ao organismo, após exposição, dependem da dose a que o indivíduo foi exposto, da quantidade que foi absorvida, das características próprias de cada organismo, do processo de metabolismo e da excreção, entre outros (BRASIL, 2014). A exposição a doses elevadas pode danificar o fígado e os rins, irritar as membranas mucosas (tecido que reveste as cavidades internas do corpo) e causar alterações no sistema neurológico (GARABRANT; PHILBERT, 2002). Foi observado retardo mental, 
como resultado da exposição pré-natal ao 2,4-D (CASEY; COLLIE, 1984; KIM; KEIZER; PRITCHARD, 1988).

Entre os fazendeiros, o herbicida à base de glifosato é o segundo mais utilizado. Análises de correlação levantaram preocupações sobre possíveis conexões entre o uso de glifosato e vários efeitos sobre o bem-estar e doenças, como hipertensão, diabetes, acidentes vasculares cerebrais, autismo, insuficiência renal, doenças de Parkinson e Alzheimer e câncer. Além disso, existem preocupações sobre a possível capacidade do glifosato em causar intolerância ao glúten, problemas reprodutivos e aumento do risco de desenvolver linfoma não Hodgkin (um tipo de câncer que se desenvolve nos gânglios linfáticos) (SAMSEL; SENEFF, 2013). Recentemente, países europeus, como os Países Baixos, a Dinamarca e a Suécia, baniram ou restringiram o uso de glifosato.

A maior parte dos alimentos de origem animal (leite ou produtos lácteos, ovos, carne ou processados) consumidos no Brasil apresentam resíduos de cipermetrina, cuja origem é a aplicação tópica no gado ou os resíduos presentes em rações de animais produzidas a partir de soja ou milho, entre outros (WHO, 1989; BRASIL, 2016). A degradação biológica da cipermetrina é rápida. Isso significa que, quando aplicado nas concentrações recomendadas, o produto e seus resíduos no solo e nas águas superficiais são muito baixos. Os riscos de bioacumulação (absorção por organismos vivos) nas cadeias tróficas também são baixos. Em peixes, por exemplo, a absorção e eliminação da cipermetrina ocorrem em poucas semanas. Por conseguinte, o risco de intoxicação do consumidor por meio de alimentos é igualmente baixo (CARRIQUIRIBORDE et al., 2007; WHO, 1989).

A cipermetrina age como neurotoxina, tendo como alvo o sistema nervoso central do inseto. A exposição de organismos não alvo ao produto pode produzir efeitos similares, em diferentes escalas (PASCUAL; PERIS, 1992). A exposição humana aguda, pelo contato com a pele, inalação ou ingestão, é bastante variável e depende de fatores como idade, sexo e condições ambientais (EMEA, 2002). Em certos casos, a intoxicação induz uma atividade repetitiva pronunciada caracterizada por tremor, hipersensibilidade, movimentos involuntários e incontroláveis e salivação (MIYAMOTO et al., 1995). As doses ingeridas acidentalmente são excretadas pela urina e pelas fezes no prazo de um dia (CRAWFORD; CROUCHER; HUTSON, 1981), o que reduz o risco de morte. O inseticida pode causar danos ao DNA e atravessar a barreira uteroplacentária, produzindo efeitos teratogênicos (malformações) em embriões (BHUNYA; PATI, 1988; KHURSHID, 2003).

Além dos trabalhadores rurais, que preparam, manuseiam e pulverizam os agrotóxicos, fazem parte dos grupos em situação de risco também as 
famílias dos agricultores, porque geralmente residem em locais próximos ao ambiente de trabalho e são mais suscetíveis ao contato com os produtos por meio do manuseio de Equipamentos de Proteção Individual (EPI) ou roupas contaminadas (CARVALHO, 2006). Cabe ressaltar que, de forma geral, o uso de EPI é dispensado pelos agricultores da região de Alta Floresta, que reclamam da dificuldade de se adaptar a vestimentas que, segundo eles, são produzidas para serem usadas em outros ambientes, diferentes das condições de alta temperatura e umidade da Amazônia.

A exposição da população urbana ocorre principalmente por meio da ingestão de alimentos e água contaminada com resíduos de pesticidas. Além disso, existe uma exposição substancial que acontece dentro ou ao redor das residências (DAMALAS; ELEFTHEROHORINOS, 2011). Em cidades de Mato Grosso, como Sorriso e Campo Verde, a questão é preocupante, pois, em muitas delas, as lavouras de soja terminam onde começam as cidades.

\section{PERCEPÇÕES DE RISCO}

A recente democratização do debate sobre os riscos à saúde, promovida principalmente pela mídia por meio de revistas, da ampliação acesso à internet e de programas de rádio, entre outros (KLANOVICZ, 2010), criou uma imagem negativa sobre a prática do uso de agrotóxicos. Esse processo contribui para um significativo silenciamento dos agricultores familiares. Um exemplo é o fato de que $50,75 \%$ dos agricultores familiares optaram por não responder às questões relacionadas ao uso de agroquímicos em nossa pesquisa. Em contrapartida, entre os fazendeiros, 90,25\% manifestaram-se em relação à questão.

Essa distinção ocorre possivelmente porque os agricultores familiares mantêm uma relação mais estreita com os consumidores, por produzirem uma parcela importante dos alimentos que vão diretamente à mesa e em localidades próximas aos centros de comercialização. O silêncio e, em alguns casos, a negação do uso, são estratégias usadas pelo agricultor para evitar o afastamento do consumidor, que poderia ser causado pela veiculação de informações negativas, em grupos sociais e pela mídia. Entre os fazendeiros, a pressão dos consumidores locais é sentida em menor intensidade, uma vez que esses atendem às determinações de outros mercados.

Quando se trata, no entanto, de avaliar o futuro da região face à expansão das lavouras de grãos, os agricultores familiares são menos reticentes. Suas percepções sobre as principais mudanças que poderão ser colocadas em curso incluem, principalmente, a preocupação com a ampliação do uso de pesticidas. 
Nas lavouras, os grandes produtores "usam muito veneno, o que pode acabar com alguns insetos", produzir "escassez de alimento orgânico e produtos orgânicos", "degradar rios" e "aumentar o número de pragas" - são as expressões de alguns dos entrevistados.

Os agricultores familiares se preocupam preponderantemente com o que está fora de suas propriedades, em termos de efeitos do uso de agrotóxicos, sobretudo no que signifique uma ameaça à qualidade de vida dos filhos, em um cenário futuro (SLOVIC; WEBER, 2002). Em suas percepções, há uma minimização dos riscos associados ao seu próprio uso de pesticidas, em comparação com os danos que serão causados pela incorporação de safras de soja e milho. Em termos quantitativos, a avaliação se mostra verdadeira, uma vez que o volume de pesticidas aplicados nas culturas geneticamente modificadas, diante da extensão das áreas produtivas, é espantosamente maior que aquele pulverizado nas pequenas propriedades, mesmo quando essas últimas fazem uso extensivo de herbicidas para o controle de plantas indesejáveis em pastagens.

A diferença ocorre, igualmente, porque o número anual de pulverizações nas lavouras de grãos é vertiginosamente maior que as realizadas nas pastagens. Pesquisa sobre a comercialização de pesticidas realizada na cidade de Alta Floresta por Silva et al. (2011) indica que, no município, a quantidade de ingredientes ativos de herbicidas destinados a pastagens chega a 145 mil quilos por ano. A correlação entre os dados da pesquisa sobre a quantidade comercializada e os dados do IBGE sobre a área destinada a pastagens mostra que cada hectare recebe, em média, $0,5 \mathrm{~kg}$ de herbicida por ano, com significativa predominância da fórmula 2,4-D + Picloram (IBGE, 2006; SILVA et al., 2011).

A dinâmica observada em outros municípios produtores de grãos nos ajuda a conhecer a amplitude dos prejuízos causados pelo uso de herbicidas nas lavouras de soja de Mato Grosso. É emblemático o caso de Lucas do Rio Verde, um dos maiores produtores mato-grossenses de soja. No município de 37 mil habitantes foram consumidos, em 2010, cerca de 5,1 milhões de litros de agrotóxicos, em 420 mil hectares de lavouras de soja, milho e algodão (IBGE, 2011; INDEA-MT, 2011 apud MOREIRA et al., 2012). A exposição a agrotóxicos por habitante/ano foi calculada em 136 litros. Resíduos desses produtos têm sido encontrados em amostras de água de poço, de chuva e de ar, coletadas em escolas do município (MOREIRA et al., 2010).

A percepção de que a quantidade de produtos utilizados seja o principal responsável por efeitos maléficos à saúde não pode, entretanto, abrandar a importância do tipo de produto utilizado, nem os riscos associados à forma com que esse é aplicado na agricultura familiar. Em certos casos, as superdoses de 
agrotóxicos, associadas à exposição direta e, por vezes, prolongada do trabalhador, sem a devida proteção, podem afetar de forma mais intensa a saúde dos grupos expostos do que a exposição aos grandes volumes de agrotóxicos usados nas lavouras (KAMEL; HOPPIN, 2004).

Uma das preocupações dos agricultores familiares, em relação à expansão das lavouras de grãos na região de Alta Floresta, é a pulverização por meio da aviação agrícola. A preocupação centra-se no desvio de pesticidas associado à aplicação aérea. No norte e nordeste do estado, onde predomina a pecuária de leite e corte, há registros de "chuvas de agrotóxicos" que afetaram pequenas propriedades em Nova Guarita (FREITAS, 2016) e no território do povo Xavante de Marãiwatsédé, em Alto Boa Vista (LIMA, 2015). Em todos esses casos, as áreas foram atingidas por pulverizações realizadas em propriedades circunvizinhas. Por vezes, a persistência dos herbicidas no solo provocou perdas na produção atingida por mais de dois anos, afetando, em situações críticas, parte considerável da renda da família de agricultores (FERREIRA, 2015). Em relação ao futuro, "O uso de veneno pelas redondezas vai nos prejudicar", "vai ser péssimo para a nossa produção", porque pode "cair nos pastos e prejudicar o capim”, ou seja, "os produtores vão ganhar dinheiro, enquanto nós vamos ficar envenenados", conforme comentaram alguns dos agricultores familiares entrevistados.

O uso atual de inseticidas, como tiametoxam e cipermetrina, preocupam especialmente os produtores de mel. A atividade está em ascensão na região. Um projeto desenvolvido pela Prefeitura Municipal de Alta Floresta, com apoio do Fundo Amazônia ${ }^{4}$, distribuiu a agricultores familiares 381 colmeias de abelhas melíponas (abelhas nativas sem ferrão), incentivando-os a multiplicá-las e redistribuí-las (RODRIGUES, 2016). Iniciativas semelhantes têm promovido a criação de Apis mellifera, o que tem permitido ampliar a produção regional de mel e, consequentemente, aumentar a geração de renda na agricultura familiar, uma preocupação presente nos discursos de instituições públicas municipais e do terceiro setor local, diante do risco eminente de ampliação do êxodo rural.

Um incidente ocorrido em 2017, em uma propriedade produtora de mel da Comunidade Nossa Senhora de Guadalupe, na zona rural de Alta Floresta, obrigou os agricultores a buscar outras áreas para instalar as colmeias. A propriedade faz divisa com uma fazenda produtora de soja e, após uma das pulverizações da

\footnotetext{
O Fundo Amazônia fomenta ações de prevenção, monitoramento e combate ao desmatamento, e de promoção da conservação e do uso sustentável das florestas da Amazônia Legal. Os recursos são geridos pelo Banco Nacional de Desenvolvimento Econômico e Social (BNDES), o qual se incumbe de captar doações internacionais, contratar e monitorar os projetos e ações apoiados. Na região de Alta Floresta foram investidos cerca de $\mathrm{R} \$ 100$ milhões, por meio de projetos geridos por quatro organizações (Prefeitura Municipal de Alta Floresta, Prefeitura Municipal de Carlinda, Instituto Centro de vida e Instituto Ouro Verde).
} 
lavoura, houve perda de cerca de 30 colmeias (25\% da produção) de Apis mellifera (PRODUTOS ORGÂNICOS..., 2017). O caso foi denunciado ao Ministério Público. Na mesma propriedade, o uso de pesticidas nas fazendas da vizinhança ameaça, segundo um dos agricultores, a perda da certificação orgânica de café, obtida junto ao Ministério da Agricultura, Pecuária e Abastecimento (MAPA) (informação verbal) ${ }^{5}$.

"O veneno pode prejudicar as coisas que os familiares fazem, o plantio da horta, por exemplo" (AF_31), comentou um dos agricultores. Esses prejuízos estão relacionados principalmente ao risco de deriva dos herbicidas em culturas não alvo. Nos Tribunais de Justiça dos estados da região Sul do país, por exemplo, correm diversos processos de apelação cível para o reparo do dano (parcial ou total) causado a plantações de frutas, sobretudo safras de uva, decorrentes da conduta inadequada na aplicação aérea de herbicidas em propriedades vizinhas, produtoras de grãos (ARAÚJO, 2018).

Em longo prazo, os agricultores preocupam-se, igualmente, com a redução das populações de espécies de abelhas polinizadoras devido à deriva de inseticidas. Pesquisas indicam que a redução em $30 \%$ na prestação de serviços de polinização é suficiente para causar a diminuição no número de sementes e danos ao tamanho, forma e conjunto de frutos (STANLEY et al., 2015). Produtores de maracujá de Paranaíta, por exemplo, estão realizando a polinização das flores de forma manual, depois de constatada a expressiva redução da população de mamangavas, o principal agente polinizador natural.

Em última instância, os agricultores "exprimidos" pelas grandes lavouras, como foi citado várias vezes, podem ter de "migrar para outros lugares, como foi no Paraná na década de 1970". "É um engano acreditar que a vinda da soja vai melhorar a vida de quem trabalha ou mora no campo" (AF_54). "Pode ter uma pressão para as famílias arrendarem as terras e irem pra cidade. Eu não gosto da cidade e as pessoas não voltam mais para o campo, porque não podem mais. Eu já me senti pressionada" (AF_38). A história desse "aperto" dos pequenos proprietários de terra pelas grandes empresas produtoras de grãos (por exemplo, Amaggi, Bom Futuro etc.), é descrita em diversos municípios matogrossenses, como Sorriso, onde empresas que cultivam vastas áreas (por exemplo, 30.000 hectares ou mais), com a aplicação de capital de investidores externos, consomem as terras dos pequenos e médios produtores (IORIS, 2016). Em regiões de conflito, há registros de casos em que a pulverização ex situ foi usada irregularmente como mecanismo de descapitalização, seguida da manifestação

5 Informação fornecida por A. A. da Silva, agricultor, em 05 de fevereiro de 2017. 
de interesse de aquisição das menores propriedades pelos grandes latifúndios (DABAT, 2014; FREITAS, 2016).

Para além do sentimento de intranquilidade relacionado aos riscos, existe certo contentamento de alguns agricultores em relação à expansão das lavouras. Neste caso, destacam-se pontos positivos de uma possível redução do valor final do milho, o que poderá diminuir os investimentos dos agricultores familiares em ração para o gado; o crescimento de vagas de trabalho, para aqueles que complementam a renda obtida na propriedade, com a prestação de serviços a terceiros; e a melhoria das estradas, diminuindo os investimentos na escoação da produção, como o leite, por exemplo.

Esses pontos foram igualmente citados pelo conjunto de fazendeiros, grupo que não apontou quaisquer tipos de riscos. Para a ampla maioria desse grupo, a expansão das lavouras de grãos promoverá o "desenvolvimento econômico em todos os aspectos" (F_4), podendo melhorar as técnicas de produção - "modo de plantar, adubar, melhoramento da terra" (F_17) -, abrindo "um horizonte novo, cheio de oportunidades, no qual a agricultura familiar poderá produzir soja e ganhar com a valorização dos imóveis rurais" (F_13).

\section{CONSIDERAÇÕES FINAIS}

Desde a primeira fase da ocupação agrícola da região de Alta Floresta, a agricultura se configura em uma atividade de risco, sobretudo devido ao costume do uso de agrotóxicos, trazido pelos colonos da região Sul do país. De fato, nos anos 1970, os pesticidas ofereciam uma insegurança muito maior aos agricultores e trabalhadores rurais, relacionada principalmente ao uso de organoclorados, cujas consequências para a saúde eram completamente desconhecidas, como também eram desconhecidas as medidas de precaução (uso de EPI etc.). O que foi ampliado, daquele primeiro momento aos dias atuais, foi a percepção dos riscos à saúde, produzidos pela incorporação dos meios industriais de produção.

Essa ampliação da percepção dos riscos é produzida, entre outros fatores, pelo maior acesso à informação ou, ainda, pelo acesso a informações mais qualificadas sobre os perigos que foram - e estão sendo - incorporados ao modo de vida rural. Mas, se todos os grupos têm acesso à informação, por que os agricultores familiares estão mais preocupados com as externalidades negativas produzidas pela expansão das lavouras de grãos? A resposta a essa questão confirma a primeira hipótese do estudo. A maior preocupação com as externalidades negativas associadas à disseminação do uso de agrotóxicos parece 
estar na relação que o grupo estabelece com a natureza. A agricultura familiar tem raízes culturais no campesinato. Assim, mesmo tendo absorvido os princípios da agricultura moderna, carrega, em si, em distintas proporções e contradições, valores éticos e morais próprios dos modos de vida camponeses, os quais foram moldados por milênios de convivência com a natureza.

Esses valores, embora definam a percepção dos agricultores familiares em relação aos riscos, não necessariamente modificam a sua prática. Há, nesse sentido, uma ligeira aceitação dos agrotóxicos nas pequenas propriedades explicada por uma necessidade econômica, que se sobrepõe aos valores da relação com a terra e a natureza. Em síntese, o que incomoda o grupo são os riscos associados ao volume de agrotóxicos que são normalmente aplicados nas grandes propriedades, bem como as ameaças desse modelo de produção ao sistema familiar, o que confirma a segunda hipótese do estudo.

Os fazendeiros, por sua vez, se apegam à segurança técnica e na percepção de que os riscos pouco e raramente os atingem. A maioria desse grupo reside fora da propriedade - em alguns casos, fora da região -, o que lhes condiciona um afastamento da zona de maior risco, face aos tipos e quantidades de agrotóxicos aplicados pelos trabalhadores que contratam. É ilusória, entretanto, a percepção de que o grupo esteja livre da exposição aos contaminantes. Ainda que em menor grau, esses produtores e suas famílias estão expostos aos resíduos dos pesticidas e suas combinações no ambiente por meio do ar que respiram e da água e do alimento que consomem, incluindo os alimentos processados (carnes, laticínios etc.).

\section{Agradecimentos}

Aos agricultores familiares e fazendeiros, participantes da pesquisa.

Ao Instituto Centro de Vida.

A Karla Sessin Dilascio, Irene Duarte, Eriberto Muller, Charles Borges Rossi e Cícero Rogério Henrique Laluce, que contribuíram com o desenho da pesquisa e a coleta de dados.

Aos acadêmicos dos cursos de Ciências Biológicas, Engenharia Florestal, Agronomia e Direito, da UNEMAT, que voluntariamente contribuíram com a coleta de dados.

Ao Sustainable Trade Initiative (IDH), pelos recursos de custeio da pesquisa. 


\section{REFERÊNCIAS}

ARAÚJO, E. Efeitos da deriva de agrotóxicos oriunda de atividade agrícola no município de Rio Sono (TO) e avaliação da legislação quanto à deriva dessas substâncias para a flora de áreas protegidas de imóveis rurais. 2018.84 f. Dissertação (Mestrado em Biodiversidade, Ecologia e Conservação) - Programa de Pós-Graduação em Biodiversidade, Ecologia e Conservação, Universidade Federal do Tocantins, Porto Nacional, 2018.

BECK, Ü. Sociedade de risco: rumo a uma outra modernidade. São Paulo: Ed. 34, 2010.

BECKER, B. K. Significância contemporânea da fronteira: uma interpretação geopolítica a partir da Amazônia Brasileira. In: AUBERTIN, C. (ed.). Fronteiras. Brasília: Editora UnB, 1988. p. 60-89.

BERNASCONI, P.; ADAB, R.; MICOL, L. Diagnóstico ambiental do município de Alta Floresta - MT. Alta Floresta: ICV, 2008.

BERNASCONI, P.; SANTOS, R. R.; RODRIGUES, J. A. AAI - Avaliação Ambiental Integrada: território portal da Amazônia. Alta Floresta: ICV, 2009.

BHUNYA, S. P.; PATI, P. C. Genotoxic effects of a synthetic pyrethroid insecticide, cypermethrin, in mice in vivo. Toxicology Letters, [S. l.], v. 41, n. 3, p. 223-230, jun. 1988.

BRASIL. Portaria n ${ }^{\circ}$ 329, de 02 de setembro de 1985. Brasilia, DF: Ministério da Agricultura, [1985]. Disponível em: http://www.camara.gov.br/proposicoesWeb/ prop_mostrarintegra;jsessionid $=$ F540106D5CD1777FB30619F3F2D6FD4A.nod e1 codteor=620544\&filename $=$ Avulso+-PL+4336/2008. Acesso em: 08 fev. 2017.

BRASIL. Portaria $\mathbf{n}^{\circ}$ 11, de 08 de janeiro de 1998. Institui, no âmbito do Ministério do Trabalho, Comissão Tripartite para efetuar análise da Convenção no 174 e Recomendação no 181, da OIT. Brasília, DF: [1998]. Disponível em: https://www.normasbrasil.com.br/norma/portaria-11-1998_181290.html. Acesso em: 08 fev. 2017.

BRASIL. Estudo propositivo: Território Portal da Amazônia. Brasília: Ministério do Desenvolvimento Agrário/Fundação Cândido Rondon, 2005.

BRASIL. Portaria $\mathbf{n}^{\circ}$ 96, de 27 de março de 2008. Considera os municípios dos Estados que menciona, como municípios abrangidos pelo Bioma Amazônia. Brasília, DF: Ministério do Meio Ambiente, [2008]. Disponível em: http:// www.fundoamazonia.gov.br/FundoAmazonia/export/sites/default/site_pt/ Galerias/Arquivos/Downloads/Portaria_MMA_96_08_DEFINIxO_DO_ BIOMA_AMAZxNIA.pdf. Acesso em: 06 fev. 2017. 
BRASIL. Ministério da Saúde. Fundação Oswaldo Cruz. Instituto Nacional de Controle de Qualidade em Saúde. Parecer técnico. Avaliação dos efeitos tóxicos sobre o sistema reprodutivo, hormonal e câncer para seres humanos após o uso do herbicida 2,4-D. Rio de Janeiro: Fundação Oswaldo Cruz, maio 2014. Disponível em: http://antigo.contraosagrotoxicos.org/index.php/ materiais/relatorios/parecer-sobre-o-herbicida-2-4-d-incqs-fiocruz/download. Acesso em: 10 jul. 2018.

BRASIL. Resultados gerais do subprograma de monitoramento e subprograma exploratório do Plano Nacional de Controle de Resíduos e Contaminantes-PNCRC 2016. Ministério da Agricultura, Pecuária e Abastecimento, Brasília, DF, 2016. Disponível em: https://www.gov.br/agricultura/pt-br/assuntos/inspecao/ produtos-animal/plano-de-nacional-de-controle-de-residuos-e-contaminantes/ documentos-da-pncrc/resultados-pncrc-2016-2.pdf. Acesso em: 11 jul. 2018.

CARRIQUIRIBORDE, P.; DÍAZ, J.; MUGNI, H.; BONETTO, C.; RONCO, A. E. Impact of cypermethrin on stream fish populations under field-use in biotechsoybean production. Chemosphere, [S. l.], v. 68, n. 4, p. 613-621, jun. 2007.

CARVALHO, F. P. Agriculture, pesticides, food security and food safety. Environmental Science \& Policy, [S. l.], v. 9, n. 7-8, p. 685-692, Nov. 2006.

CASEY, P. H.; COLLIE, W. R. Severe mental retardation and multiple congenital anomalies of uncertain cause after extreme parental exposure to 2,4-D. The Journal of Pediatrics, [S. l.], v. 104, n. 2, p. 313-315, Feb. 1984.

COY, M.; KLINGLER, M. Frentes pioneiras em transformação: o eixo da BR163 e os desafios socioambientais. Revista Territórios e Fronteiras, Cuiabá, v. 7, n. 1, p. 1-26, abr. 2014.

CRAWFORD, M. J.; CROUCHER, A.; HUTSON, D. H. Metabolism of cisand trans-cypermethrin in rats. Balance and tissue retention study. Journal of Agricultural and Food Chemistry, [S. l.], v. 29, n. 1, p. 130-135, Feb. 1981.

DABAT, C. "É a parte que te cabe deste latifúndio": Acesso precário e limitado a terra para os trabalhadores rurais da zona canavieira de Pernambuco. Tempos Históricos, Marechal Cândido Rondon, v. 18, p. 191-216, 2014.

DALLA VILLA, R.; DE CARVALHO DORES, E. F.; CARBO, L.; CUNHA, M. L. Dissipation of DDT in a heavily contaminated soil in Mato Grosso, Brazil. Chemosphere, [S. l.], v. 64, n. 4, p. 549-554, July 2006. 
DAMALAS, C. A.; ELEFTHEROHORINOS, I. G. Pesticide exposure, safety issues, and risk assessment indicators. International Journal of Environmental Research and Public Health, [S. l.], v. 8, n. 5, p. 1402-1419, May 2011.

D'AMATO, C.; TORRES, J. P. M.; MALM, O. Determinação de EDDT encontradas em peixes comestíveis de diferentes áreas da Amazônia brasileira. Oecologia Brasiliensis, Rio de Janeiro, v. 11, n. 2, p. 202-212, 2007.

EMEA. Committee for Veterinary Medicinal Products: Cypermethrin. European Medicines Agency, Amsterdan, 2002. Disponível em: https:/ /www. ema.europa.eu/en/documents/mrl-report/cypermethrin-summary-reportcommittee-veterinary-medicinal-products_en.pdf. Acesso em: 08 fev. 2017.

FERREIRA, M. L. P. C. A pulverização aérea de agrotóxicos no Brasil: cenário atual e desafios. Revista de Direito Sanitário, v. 15, n. 3, p. 18, 14 abr. 2015.

FORTES, P. A. C.; RIBEIRO, H. Saúde global em tempos de globalização. Saúde e Sociedade, São Paulo, v. 23, n. 2, p. 366-375, jun. 2014.

FREITAS, L. M. Pulverização aérea com agrotóxicos: acidente ou crime? 2016. 111 f. Dissertação (Mestrado em Saúde Pública) - Escola Nacional de Saúde Pública Sérgio Arouca, Fundação Oswaldo Cruz, Rio de Janeiro, 2016.

GARABRANT, D. H.; PHILBERT, M. A. Review of 2,4-dichlorophenoxyacetic acid (2,4-D) epidemiology and toxicology. Critical Reviews in Toxicology, [S. l.], v. 32, n. 4, p. 233-257, July 2002.

GIDDENS, A. As conseqüências da modernidade. São Paulo: UNESP, 1991. GOLDBLATT, D. Teoria social e ambiente. Lisboa: Instituto Piaget, 1996.

GRAZIANO DA SILVA, J. A modernização dolorosa. Rio de Janeiro: Zahar, 1982.

GUIMARÃES NETO, R. B. A lenda do ouro verde: política de colonização no Brasil contemporâneo. Cuiabá: UNICEN, 2002.

HANNIGAN, J. A. Sociologia ambiental: a formação de uma perspectiva social. Lisboa: Instituto Piaget, 1995.

HARNER, T.; WIDEMAN, J. L.; JANTUNEN, L. M.; BIDLEMAN, T. F; PARKHURST, W. J. Residues of organochlorine pesticides in Alabama soils. Environmental Pollution, [S. l.], v. 106, n. 3, p. 323-332, Sept. 1999.

IBGE. Censo agropecuário 2006. IBGE, Rio de Janeiro, 2006. Disponível em: http://www.sidra.ibge.gov.br/bda/pesquisas/ca/default.asp?o $=2 \& i=\mathrm{P} \# 13$. Acesso em: 23 jul. 2014. 
IBGE.Cidades@. IBGE, Rio de Janeiro, 2011. Disponível em: www.cidades. ibge.gov.br/. Acesso em: 10 fev. 2017.

IBGE. Cidades@. IBGE, Rio de Janeiro, 2019. Disponível em: www.cidades. ibge.gov.br/. Acesso em: 06 jun. 2020.

IGNOTTI, E.; HACON, S.; JUNGER, W.; MOURÃO, D.; LONGO, K.; FREITAS, S.; ARTAXO, P.; LEON, A. C.; Air pollution and hospital admissions for respiratory diseases in the subequatorial Amazon: a time series approach. Cadernos de Saúde Pública, Rio de Janeiro, v. 26, n. 4, p. 747-761, abr. 2010.

IORIS, A. A. R. Rent of agribusiness in the Amazon: A case study from Mato Grosso. Land Use Policy, [S. l.], v. 59, p. 456-466, Dec. 2016.

JEPSON, W. Private agricultural colonization on a Brazilian frontier, 1970-1980. Journal of Historical Geography, [S. l.], v. 32, n. 4, p. 839-863, Oct. 2006.

KAMEL, F; HOPPIN, J. A. Association of Pesticide Exposure with Neurologic Dysfunction and Disease. Environmental Health Perspectives, [S. l.], v. 112, n. 9, p. 950-958, May 2004.

KHURSHID, A. Cypermethrin, a Pyrethroid Insecticide Induces Teratological and Biochemical Changes in Young Chick Embryos. Pakistan Journal of Biological Sciences, [S. l.], v. 6, n. 19, p. 1698-1705, Dec. 2003.

KIM, C. S.; KEIZER, R. F.; PRITCHARD, J. B. 2,4-Dichlorophenoxyacetic acid intoxication increases its accumulation within the brain. Brain Research, [S.l.], v. 440, n. 2, p. 216-226, Feb. 1988.

KLANOVICZ, J. Toxicidade e produção de maçãs no sul do Brasil. História, Ciências, Saúde-Manguinhos, Manguinhos, v. 17, n. 1, p. 67-85, mar. 2010.

LIMA, F. A. N. S. Saúde, ambiente e contaminação hídrica por agrotóxicos na terra indígena Marãiwatsédé, Mato Grosso. 2015. Dissertação (Mestrado em Saúde Coletiva) - Programa de Pós-Graduação em Saúde Coletiva, Universidade Federal de Mato Grosso, Cuiabá, 2015.

LIPOVETSKY, G.; SERROY, J. A cultura mundo, respostas a uma sociedade desorientada. Tradução M L Machado. São Paulo: Companhia das Letras, 2011. MARTIJN, A.; BAKKER, H.; SCHREUDER, R. H. Soil persistence of DDT, dieldrin, and lindane over a long period. Bulletin of Environmental Contamination and Toxicology, [S. l.], v. 51, n. 2, Aug. 1993.

MATO GROSSO. Informações Regionais de Saúde do Estado de Mato Grosso - 2009/2010. Cuiabá: Secretaria de Estado de Saúde de Mato Grosso, abr. 2011. 
MATO GROSSO. Informações Regionais de Saúde do Estado de Mato Grosso - 2011/2012. Cuiabá: Secretaria de Estado de Saúde de Mato Grosso, maio 2013.

MATO GROSSO. Informações Regionais de Saúde do Estado de Mato Grosso - 2013/2014. Cuiabá: Coordenadoria de Gestão da Informação em Saúde, 2015.

MDIC. Balança comercial brasileira por município. MDIC, Brasília, DF, 2016. Disponível em: http://www.desenvolvimento.gov.br//sitio/sistema/balanca/. Acesso em: 12 maio 2018.

MERLEAU-PONTY, M. Fenomenologia da percepção. Tradução de Carlos Alberto Ribeiro de Moura. São Paulo: Martins Fontes, 1994.

MIRANDA, M. O papel da colonização dirigida na expansão da fronteira agrícola na Amazônia. In: BECKER, B. K.; MIRANDA, M.; MACHADO, L. O. (org.). Fronteira amazônica: questões sobre a gestão do território. Brasília: Ed. UnB, 1990. p. 47-62.

MIYAMOTO, J. et al. Pyrethroids, nerve poisons: how their risks to human health should be assessed. Toxicology Letters, [S. l.], v. 82-83, p. 933-940, Dec. 1995. MOREIRA, J. C.; PERES, F.; PIGNATI, V.; DORES, E. F. Avaliação do risco à saúde humana decorrente do uso de agrotóxicos na agricultura e pecuária na região Centro-Oeste. Brasília, DF: CNPq, 2010.

MOREIRA, J. C.; PERES, F.; SIMÕES, A. C.; PIGNATI, W.; DORES, E.; VIEIRA, S.; STRUSSMANN, C.; MOT'T, T. Contaminação de águas superficiais e de chuva por agrotóxicos em uma região de Mato Grosso. Ciência \& Saúde Coletiva, Manguinhos, v. 17, n. 6, p. 1557-1568, 2012.

NÉDÉLEC, N. et al. Carlinda: do café ao leite. In: LE TOURNEAU, F.; CANTO, O. (org.). Amazônias brasileiras: situações locais e evoluções. Belém: NUMAUFPA, 2019. p. 183-202.

NÓBREGA, T. P. Corpo, percepção e conhecimento em Merleau-Ponty. Estudos de Psicologia, Natal, v. 13, n. 2, p. 141-148, ago. 2008.

OLIVEIRA, A. BR-163 Cuiabá-Santarém: geopolítica, grilagem, violência e mundialização. In: TORRES, M. (org.). Amazônia revelada: os descaminhos ao longo da BR-163. Brasília, DF: CNPq, 2005. p. 67-184. 
PASCUAL, J. A.; PERIS, S. J. Effects of forest spraying with two application rates of cypermethrin on food supply and on breeding success of the blue tit (Parus caeruleus). Environmental Toxicology and Chemistry, [S. l.], v. 11, n. 9, p. 1271-1280, Sept. 1992.

PATEL, R. The long green revolution. The Journal of Peasant Studies, [S. l.], v. 40, n. 1, p. 1-63, Jan. 2013.

PRODUTOS ORGÂNICOS de Alta Floresta são destaque em Feiras Internacionais. Nativa News, Alta Floresta, 14 jun. 2017. Destaques. Disponível em: http://www.nativanews.com.br/destaques/id-601264/produtos_organicos _de_alta_floresta_sao_destaque_em_feiras_internacionais. Acesso em: 06 jul. 2018.

RODRIGUES, J. Projeto Olhos d'água da Amazônia - Fase II. Alta Floresta: Paço Municipal, 2016.

QURRATU, A.; REEHAN, A. A Review of 2,4-Dichlorophenoxyacetic Acid (2,4D) Derivatives: 2,4-D Dimethylamine Salt and 2,4-D Butyl Ester. International Journal of Applied Engineering Research, v. 11, n. 19, p. 9946-9955, 2016.

SABOURIN, E. Interação entre políticas públicas e dinâmicas locais da agricultura familiar do Território do Portal da Amazônia - Mato Grosso. Montpellier: CIRAD, 2006.

SAMSEL, A.; SENEFF, S. Glyphosate, pathways to modern diseases II: celiac sprue and gluten intolerance. Interdisciplinary Toxicology, [S. l.], v. 6, n. 4, p. 159-184, Jan. 2013.

SILVA, J. R. R. et al. Agrotóxicos comercializados no município de Alta Floresta no triênio de 2006 a 2008. Revista de Ciências Agro-Ambientais, Cuiabá, v. 9 , n. 2, p. 283-299, 2011.

SJÖBERG, L. Risk Perception: Experts and the Public. European Psychologist, [S. l.], v. 3, n. 1, p. 1-12, Mar. 1998.

SLOVIC, P.; WEBER, E. Perception of risk posed by extreme events. Palisades. Risk Management Strategies is an Uncertain World, New York, p. 1-22, abr. 2002.

STANLEY, D. A.; GARRATT, M.; WICKENS, J.; POTTS, V.; POTTS, S. G.; RAINE, N. E. Neonicotinoid pesticide exposure impairs crop pollination services provided by bumblebees. Nature, New York, v. 528, n. 7583, p. 548-550, Dec. 2015. 
TAMBOSI, L.; SILGUEIRO, V. F.; BUT'TURI, W.; VIDAL, M. M. Uso das geotecnologias para o planejamento espacial e monitoramento da restauração florestal em Áreas de Preservação Permanente Degradadas (APPDs): experiências nos municípios de Alta Floresta, Carlinda e Paranaíta em Mato Grosso. Alta Floresta: ICV, 2016.

VEYRET, Y. Os riscos: o homem como agressor e vítima do meio ambiente. São Paulo: Contexto, 2007.

WANIEZ, P. La mortalité des populations sur les fronts pionniers agricoles du Brésil. Territoire en Mouvement, [S. l.], v. 4, p. 17-33, 2007.

WEIHS, M. Conexão (in)visível: degradação ambiental e saúde na fronteira agrícola amazônica. 2015. 185 f. Tese (Doutorado em Desenvolvimento Sustentável) - Centro de Desenvolvimento Sustentável, Universidade de Brasília, Brasília, 2015.

WEIHS, M.; SAYAGO, D. Mudanças ambientais e saúde pública: observações sobre a trajetória de uma fronteira agrícola amazônica. Fronteiras: Journal of Social, Technological And Environmental Science, Anápolis, v. 4, p. 209-2018, 2015.

WEIHS, M.; SAYAGO, D.; TOURRAND, E J.-F. Dinâmica da fronteira agrícola do Mato Grosso e implicações para a saúde. Estudos Avançados, São Paulo, v. 31, n. 89, p. 323-338, abr. 2017.

WHO, W. H. O. Cypermethrin. Geneva: World Health Organization, 1989. 
